Adeleke Victor Adedayo $0^{1,2}$

victor.adedayo@kwarapolytechnic.com

${ }^{1}$ Kwara State Polytechnic, Ilorin

Metallurgical Engineering Department

PMB 1375 Ilorin, Kwara State, Nigeria

\author{
adelekeadedayo58@yahoo.com \\ 2Obafemi Awolowo University, \\ Materials Science and Engineering \\ Department \\ lle-lfe, Osun State, Nigeria
}

\section{Kinetics of Oxyfuel Gas Cutting of Steels}

Oxyacetylene flame cutting is a relevant and widespread industrial process. The basic principles of the process lie in rapid high-temperature oxidation of the cut metal. The kinetics of the process depends, among other things, on the composition of the cut metal, the activity of the reactants. In this present work, a report of the role of carbon on the kinetics of the process is made; effects of the activities of oxyfuel gases on the flame cutting process is also elucidated. This was done by investigation of the effects of carbon content and the cutting pressures on the cutting rates of steels by the oxyacetylene cutting process. Six 10mm steel rods of different wt $\% \mathrm{C}$ were flame cut using different acetylene and oxygen pressures. The composition of the steel rods used ranged from $0.16 \mathrm{wt} \% \mathrm{C}$ to $0.33 \mathrm{wt} \% \mathrm{C}$, the acetylene pressures used ranged from $3.45 \times 10^{-2} \mathrm{~N} . \mathrm{m}^{-2}$ to $5.52 \times 10^{-2} \mathrm{~N} . \mathrm{m}^{-2}$, while oxygen pressure ranged from $2.76 \times 10^{-1} \mathrm{~N} . \mathrm{m}^{-2}$ to $3.17 \times 10^{-1} \mathrm{~N} . \mathrm{m}^{-2}$. The result shows that the cutting rates decreased with carbon content of the steel as a result of reduction of iron oxide during decarburization reactions; however, cutting rates increased with the oxyfuel pressures as a result of increased activity of oxyfuel gases with increased pressure.

Keywords: flame cutting, oxyfuel, oxyacetylene, steel oxidation, decarburization

\section{Introduction}

Thermodynamic analysis does not provide information on the rate of reactions in metallurgical processes (Upadhyaya and Dube, 1977). To study rates of reactions, kinetics is employed. The knowledge of kinetics of reactions/process is significant. An example of the importance of kinetics of metallurgical processes is found during the construction of the steel skeleton for a flour mill in Nigeria. It was planned that oxyacetylene would be used to cut the steels, and the period of execution of the job would be 6 months, based on the understanding that mild steel $(0.16 \mathrm{wt} \% \mathrm{C})$ would be used for the steel skeleton. The cost of the project should be N15.23 million. However, the client purchased medium carbon steel $(0.33$ $\mathrm{wt} \% \mathrm{C}$ ). The result was that the rate of job execution was much slower than expected. The job would require about 14 months. Also, more volumes of oxyfuel gases are required. The cost for labour, accommodation, feeding, transport, and rented equipments had doubled. Generally, cost became very high and over N13 million have to be added to initial N15.23 million. Definitely, there was a problem. The client believed this was a gimmick by the contractor to siphon fund and that $0.33 \mathrm{wt} \% \mathrm{C}$ steel should cut faster since it has a lower melting point.

The low cost of oxyfuel gas cutting equipment is one of the main reasons for its use. In oxy-fuel cutting, a cutting torch is used to heat metal to kindling temperature where the metal starts to turn cherry red. A stream of oxygen then trained on the metal combines with the metal which then flows out as an oxide slag to create the kerf (Union Carbide Corp, 1975; DeGarmo et al., 1999; AWS, 1997). The cut quality depends on the torch tip size, type, and distance from the metal (AWS, 1997), the oxygen and preheat gas flow rates, and the cutting speed. However, the kinetics of the process will also depend on the oxidation process of the cut metal.

There has been considerable interest in the high temperature oxidation of metals - textbooks on this subject include Birks and Meier (1983) and Kofstad (1988). When steel is exposed to high temperature oxidation conditions (Poirier et al., 2006), a multilayer scale forms consisting of $\mathrm{FeO}$ (wustite), $\mathrm{Fe}_{3} \mathrm{O}_{4}$ (magnetite) and $\mathrm{Fe}_{2} \mathrm{O}_{3}$ (haematite) with the wustite layer next to the steel surface and haematite at the gas-scale interface, as illustrated in Fig. 1.

The mass ratios of the oxides $\mathrm{FeO} / \mathrm{Fe}_{3} \mathrm{O}_{4} / \mathrm{Fe}_{2} \mathrm{O}_{3}$ are typically 95/4/1 (Poirier et al., 2006; Suarez et al., 2006).

Paper accepted September, 2010. Technical Editor: Anselmo E. Diniz

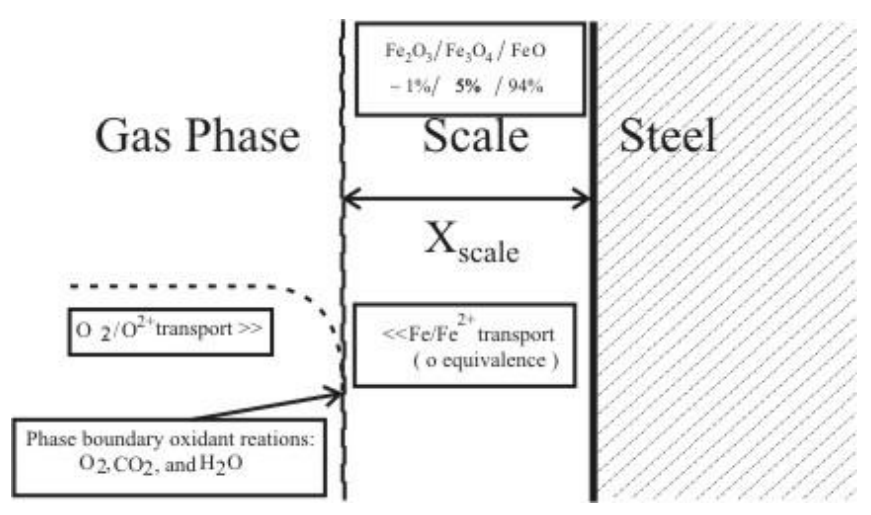

Figure 1. Mechanism of oxidation of steel.

When steel is cut by OFC-A, the iron content of the steel is oxidized to iron oxide, while the carbon content to carbon monoxide. Generally, carbon dissolved in iron is mainly oxidized to carbon monoxide (Min and Freuhan, 1992). The kinetics of the process depends, among other things, on the composition of the cut metal, and the activity of oxygen. Kinetics of oxidation of iron in molecular oxygen has been studied over a wide temperature range (Zheludkevich et al., 2004). The influence of oxygen predissociation on the activity of oxygen has also been reported. The rate of carbon oxidation, i.e. CO-formation, is found to be proportional to a steady state oxygen activity which is established on the carbon surface by the interplay of oxygen transfer reactions and carbon oxidation. This was proven in detail by Grabke (1999). Abuluwefa et al. (1997a and 1997b) studied the effects of activity of oxygen on the oxidation rates of steel at temperature range of $800^{\circ} \mathrm{C}$ to $1150^{\circ} \mathrm{C}$. It was observed that oxidation rates were reduced by lowering concentrations of free oxygen.

The activity of a substance may be defined as the ratio of fugacity of the substance to its fugacity in its standard state (Upadhyaya and Dube, 1977). Mathematically:

$$
a=f / f^{\circ}
$$

where $\mathrm{a}$ is the activity, $\mathrm{f}$ is the fugacity in any arbitrary state, and $\mathrm{f}^{\circ}$ is the fugacity in the standard state. By combining the statement of the first and second laws of thermodynamics for a system doing 
work against pressure, at constant pressure, the expression for $\mathrm{dG}$ is given as:

$$
\mathrm{dG}=\mathrm{RT} d \ln \left(\mathrm{f}^{\circ} \cdot \mathrm{a}\right)
$$

For an ideal gas, the fugacity is numerically equal to the pressure at all pressures.

In the present work, the mechanism of oxidation of steel and interaction effects of carbon on the kinetics of oxyfuel gas cutting process is discussed. The effects of cutting pressures of the oxyfuel gases are also elucidated.

\section{Nomenclature}

$\begin{array}{ll}a & =\text { activity of a substance } \\ \mathrm{A} & =\text { area of sample } \\ \mathrm{Ao} & =\text { pre-exponential factor } \\ \text { ads } & =\text { adsorption for short } \\ \boldsymbol{b} & =\text { equilibrium constant of adsorption between gas } \\ & \text { adsorbed on the surface and molecules in the gas phase. } \\ \mathrm{C} & =\text { carbon } \\ \mathrm{CO} & =\text { carbon monoxide } \\ \mathrm{CO} & =\text { carbon dioxide } \\ \text { des } & =\text { desorption for short } \\ E_{a} & =\text { activation energy for adsorption } \\ f & =\text { fugacity which is numerically equal to pressure for an } \\ & \text { ideal gas } \\ f^{\circ} & =\text { fugacity at standard state } \\ \mathrm{F} & =\text { incident molecular flux } \\ \mathrm{Fe} & =\text { iron } \\ \mathrm{FeO}_{\mathrm{O}} & =\text { iron (II) oxide (Wustite) } \\ \mathrm{Fe}_{2} \mathrm{O}_{3} & =\text { iron (III) oxide (Haematite) } \\ \mathrm{Fe}_{3} \mathrm{O}_{4} & =\text { iron (II, III) oxide (Magnetite) }\end{array}$

$$
\begin{aligned}
& \text { G = free energy } \\
& k^{\prime}=\text { rate constant } \\
& \mathrm{O}_{2} \quad=\text { oxygen } \\
& P \quad=\text { pressure, } \mathrm{Nm}^{-2} \\
& r d s \quad=\text { acronym for Rate Determining Step } \\
& R \quad=\text { gas constant } \\
& S \quad=\text { sticking probability } \\
& t \quad=\text { time } \\
& T \quad=\text { absolute temperature, } K \\
& \text { wt } \quad \text { weight } \\
& x \quad=\text { kinetic order of reaction, dimensionless } \\
& X \quad=\text { increase in scale thickness }
\end{aligned}
$$

\section{Greek Symbols}

$\begin{array}{ll}\% & =\text { percentage } \\ \theta & =\text { surface coverage of adsorbed molecules/atoms }\end{array}$

\section{Experimental Procedure}

The hot-rolled $10 \mathrm{~mm}$ metallurgy steel rods that were used in this study were procured from the Universal Steel Rolling Mill, Ogba-Ikeja, Lagos, Nigeria. These were cut into $0.2 \mathrm{~m}$ long specimen. The compositions of the steel rods are given in Table 1. At the required pressures, cutting torch is used to heat the steel rods surface to kindling temperature where the steel rods start to turn cherry red. Oxygen is then released by depressing the oxygen lever to react with the metal which then flows out of the cut (kerf) as an oxide slag. The various acetylene and oxygen pressures used are shown in Table 2. The time taken to cut the rods is noted and recorded using a stop watch. The cutting rate is calculated by finding the ratio of the diameter of rod to the total time taken, i.e.:

Cutting rate $=$ Diameter of rod $/$ total time of cut.

Table 1. Composition of steels used.

\begin{tabular}{|c|c|c|c|c|c|c|c|c|c|c|c|}
\hline SN & \multicolumn{10}{c|}{ Alloying elements (wt\%) } \\
\hline & $\mathbf{C}$ & $\mathbf{S i}$ & $\mathbf{S}$ & $\mathbf{P}$ & $\mathbf{M n}$ & $\mathbf{N i}$ & $\mathbf{C r}$ & $\mathbf{M o}$ & $\mathbf{V}$ & $\mathbf{W}$ & Fe \\
\hline 1. & 0.16 & 0.18 & 0.0589 & 0.0288 & 0.6440 & 0.1030 & 0.1244 & 0.0114 & 0.0010 & 0.0007 & Rest \\
\hline 2. & 0.18 & 0.22 & 0.0410 & 0.0237 & 0.7160 & 0.1100 & 0.1250 & 0.0220 & 0.0020 & 0.0030 & Rest \\
\hline 3. & 0.25 & 0.15 & 0.0510 & 0.0419 & 0.3658 & 0.01034 & 0.0889 & 0.0177 & 0.0003 & 0.0032 & Rest \\
\hline 4. & 0.28 & 0.18 & 0.0523 & 0.0275 & 0.6247 & 0.1170 & 0.1306 & 0.0141 & 0.0013 & 0.0035 & Rest \\
\hline $\mathbf{5 .}$ & 0.32 & 0.18 & 0.0576 & 0.0367 & 0.6494 & 0.01064 & 0.1550 & 0.0141 & 0.0024 & 0.0037 & Rest \\
\hline 6. & 0.33 & 0.31 & 0.052 & 0.0274 & 0.7523 & 0.1110 & 0.1750 & 0.0170 & 0.0030 & 0.0040 & Rest \\
\hline
\end{tabular}

\section{Results and Discussions}

Figures 2, 3, 4 and 5 show the effects of carbon content on cutting rate at different acetylene pressures, while Figs. 6, 7, 8 and 9 show the effects of oxygen pressure on cutting rate for different carbon content of cut steels. As in Fig. 2, the cutting rate was a maximum of $2.02 \mathrm{~mm} / \mathrm{min}$ at $5.52 \times 10^{-2} \mathrm{~N} \cdot \mathrm{m}^{-2}$ acetylene pressure and $3.17 \times 10^{-1} \mathrm{~N} . \mathrm{m}^{-2}$ oxygen pressure. A minimum of $1.02 \mathrm{~mm} / \mathrm{min}$. was achieved at $5.52 \times 10^{-2} \mathrm{~N} . \mathrm{m}^{-2}$ acetylene pressure and $2.76 \times 10^{-1} \mathrm{~N} . \mathrm{m}^{-2}$ oxygen pressure. In Fig. 3, a maximum of $1.90 \mathrm{~mm} / \mathrm{min}$ was achieved at $4.83 \times 10^{-2}$ N.m ${ }^{-2}$ acetylene pressure and $3.17 \times 10^{-1} \mathrm{~N} . \mathrm{m}^{-2}$ oxygen pressure for $0.16 \mathrm{wt} \% \mathrm{C}$ steel. The minimum of $0.91 \mathrm{~mm} / \mathrm{min}$ was achieved for $0.33 \mathrm{wt} \% \mathrm{C}$ steel at $4.83 \times 10^{-2} \mathrm{~N} . \mathrm{m}^{-2}$ acetylene pressure and $2.76 \times 10^{-1} \mathrm{~N} . \mathrm{m}^{-2}$ oxygen pressure. Figure 4 shows that the maximum cutting rate is $1.82 \mathrm{~mm} / \mathrm{min}$ for $0.16 \mathrm{wt} \% \mathrm{C}$ steel at $4.14 \times 10^{-2} \mathrm{~N} . \mathrm{m}^{-2}$ acetylene and $3.17 \times 10^{-1} \mathrm{~N} . \mathrm{m}^{-2}$ oxygen pressure. The minimum is $0.80 \mathrm{~mm} / \mathrm{min}$ for $0.33 \mathrm{wt} \% \mathrm{C}$ steel at $4.14 \times 10^{-2} \mathrm{~N} . \mathrm{m}^{-2}$ acetylene pressure and $2.76 \times 10^{-1} \mathrm{~N} . \mathrm{m}^{-2}$ oxygen pressure. Figure 5 has maximum cutting rate of $1.70 \mathrm{~mm} / \mathrm{min}$ at
$3.45 \times 10^{-2} \mathrm{~N} . \mathrm{m}^{-2}$ acetylene pressure for $0.16 \mathrm{wt} \% \mathrm{C}$ steel. The minimum of $0.70 \mathrm{~mm} / \mathrm{min}$ was achieved at $0.33 \mathrm{wt} \% \mathrm{C}$ steel at $3.45 \times 10^{-2} \mathrm{~N} . \mathrm{m}^{-2}$ acetylene and $2.76 \times 10^{-1} \mathrm{~N} . \mathrm{m}^{-2}$ oxygen pressure. Generally, the trend shows a decrease in cutting rates with increase in carbon content.

Generally, during hot rolling process, an oxide scale layer always develops at the steel surface. Oxidation of steel at temperatures higher than $843 \mathrm{~K}$ leads to three different iron oxide layers: wustite $(\mathrm{FeO})$, magnetite $\left(\mathrm{Fe}_{3} \mathrm{O}_{4}\right)$ and hematite $\left(\mathrm{Fe}_{2} \mathrm{O}_{3}\right)$, in oxygen content increasing order, going from substrate to free surface. Below $843 \mathrm{~K}$, only the last two are thermodynamically stable (Saurez et al., 2006). According to the literature, the relative thickness fractions of these layers between $973 \mathrm{~K}$ and $1473 \mathrm{~K}$ are 95\% wustite, $4 \%$ magnetite and $1 \%$ hematite in equilibrium (Poirier et al., 2006; Suarez et al., 2006), although this balance can vary from one case to another. Depending on temperature, time, atmosphere conditions and steel chemistry, energy barriers develop, which must be overcome for an oxide to grow (Suarez et al., 2006). 


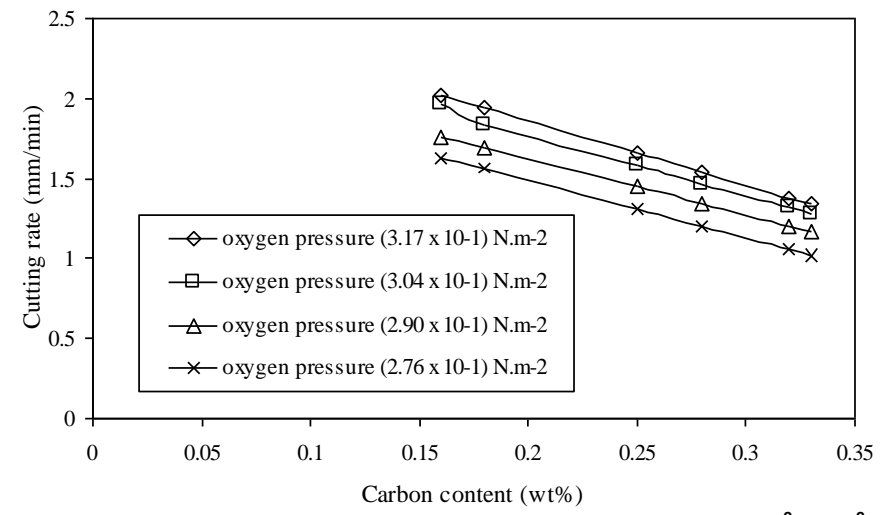

Figure 2. Effect of carbon content on cutting rate for $5.52 \times 10^{-2} \mathrm{~N} \cdot \mathrm{m}^{-2}$ acetylene pressure.

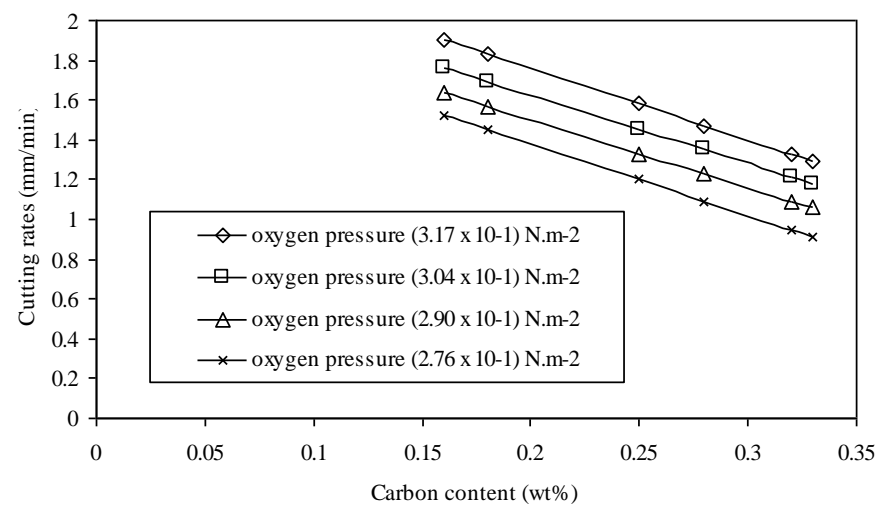

Figure 3. Effect of carbon content on cutting rate for $4.83 \times 10^{-2} \mathrm{~N} \cdot \mathrm{m}^{-2}$ acetylene pressure.

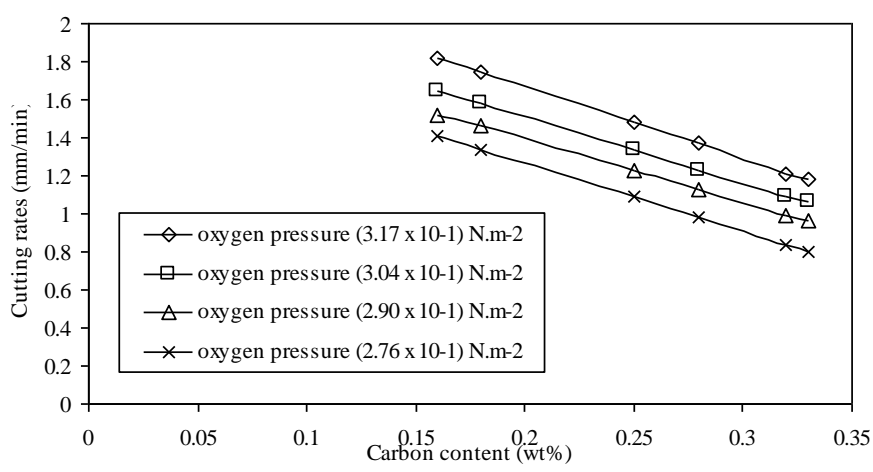

Figure 4. Effect of carbon content on cutting rate for $4.14 \times 10^{-2} \mathrm{~N}^{-\mathrm{m}^{-2}}$ acetylene pressure.

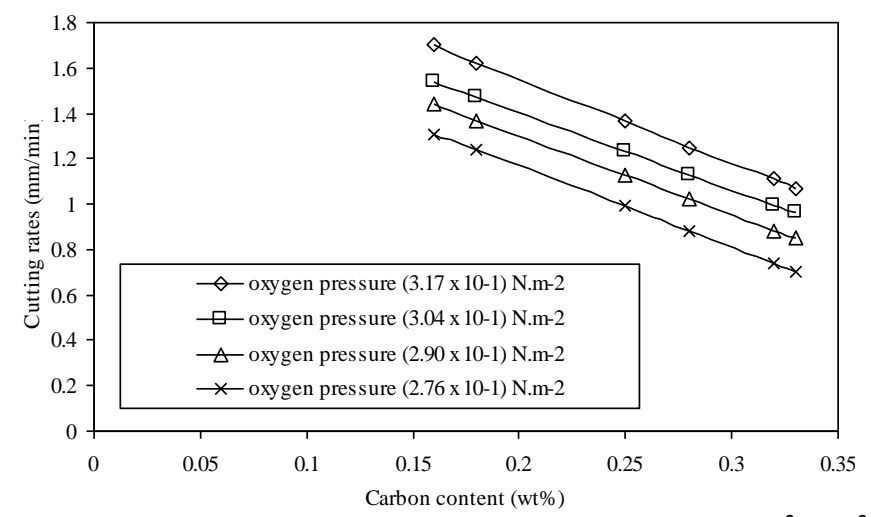

Figure 5. Effect of carbon content on cutting rate for $3.45 \times 10^{-2} \mathrm{~N} \cdot \mathrm{m}^{-2}$ acetylene pressure.

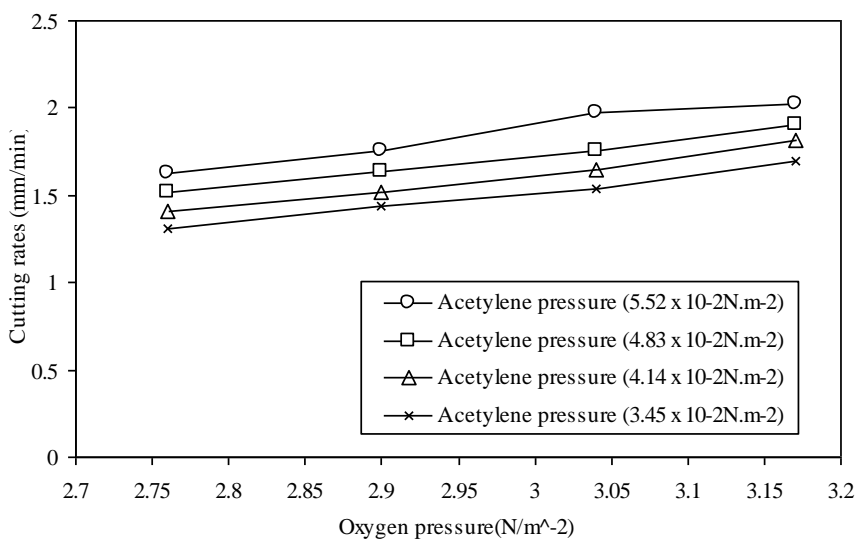

Figure 6. Effect of oxygen pressure on cutting rate for $0.16 \mathrm{wt} \% \mathrm{C}$ steel.

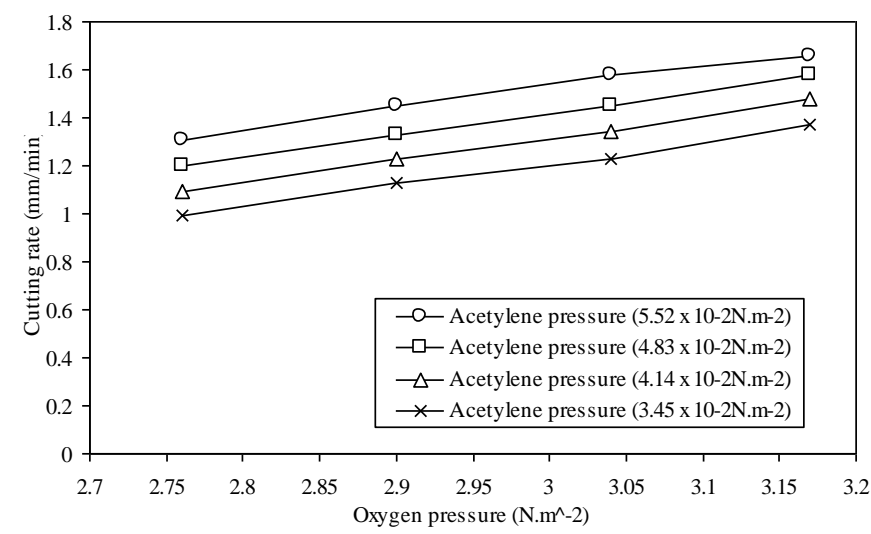

Figure 7. Effect of oxygen pressure on cutting rate for $0.25 \mathrm{wt} \% \mathrm{C}$ steel.

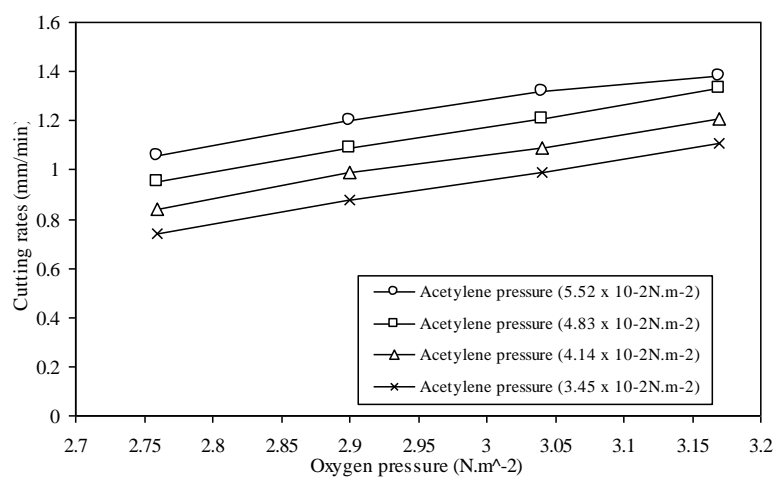

Figure 8. Effect of oxygen pressure on cutting rate for $0.32 \mathrm{wt} \% \mathrm{C}$ steel.

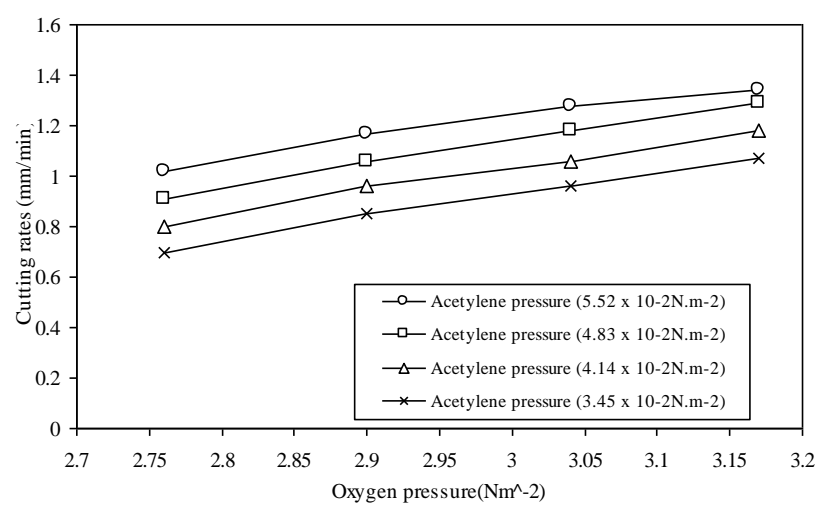

Figure 9. Effect of oxygen pressure on cutting rate for $0.33 \mathrm{wt} \% \mathrm{C}$ steel. 
Kinetics of oxidation reactions of metals at high temperatures are generally assumed to be controlled by the rates of mass transport of reactants and products in the gas-slag interface, slag-metal interface and slag phases (Mori, 1988). The passage of oxygen from the gaseous phase through the slag to the metal is generally believed to be as illustrated below in Figs. 10 and 11 .

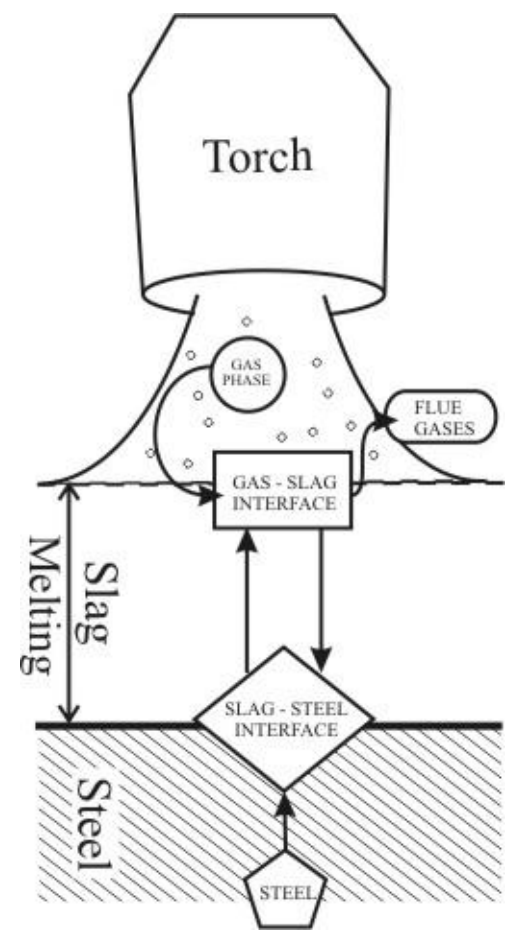

Figure 10. Pattern of interactions during flame cutting.

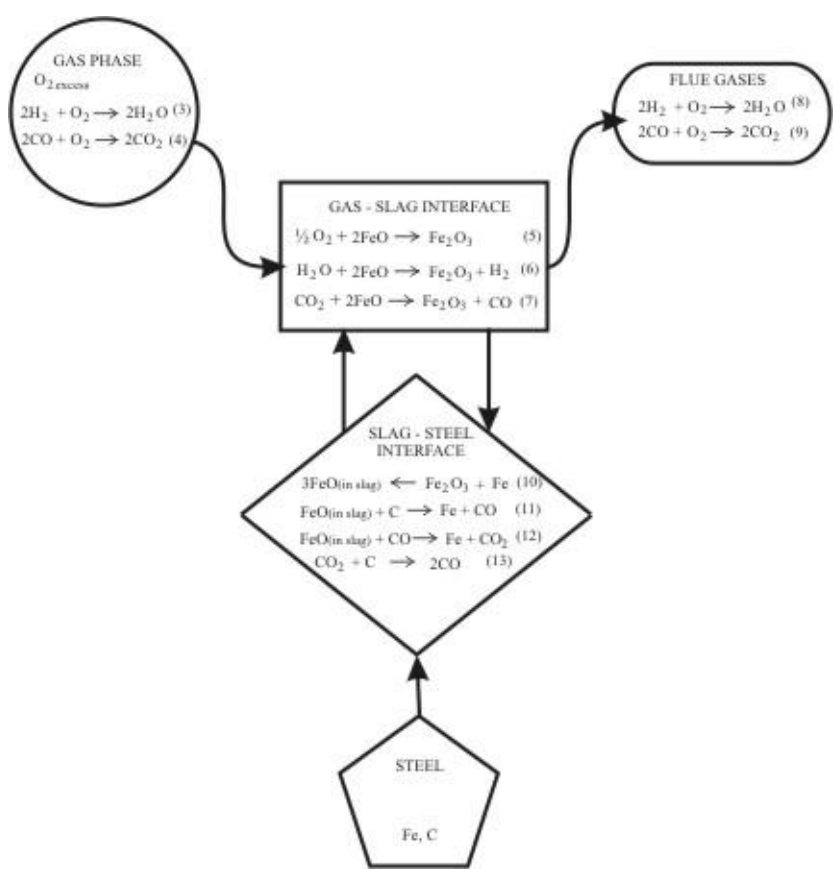

Figure 11. Reactions of slag-forming process.

However, Schwerdtfeger and Prange (1984) have shown that slag-metal reactions involving iron and/or silicon under industrial process conditions are very unlikely controlled by the transfer kinetics of the reaction. Besides, whatever the means oxidation is being achieved, cutting by oxyfuel process is achieved by melting of the slag. The cutting rate in this process will depend significantly on the rate of slag formation. Any reaction that retards formation of slag affects the cutting rate. $\mathrm{FeO}$ is a significant proportion of products of oxidation. When ferrous metals are cut by oxyacetylene, the process becomes one of rapid oxidation, i.e., burning (MIT, 2008; AWS, 1987; AWS, 1997; DeGarmo et al., 1999). The retardation of the formation of $\mathrm{FeO}$ affects the cutting rate. Reactions below (Eqs. 3 to 5) are unfavorable to the formation of $\mathrm{FeO}$.

$$
\begin{aligned}
& \mathrm{FeO}+\mathrm{C} \rightarrow \mathrm{Fe}+\mathrm{CO} \\
& \mathrm{FeO}+\mathrm{CO} \rightarrow \mathrm{Fe}+\mathrm{CO}_{2} \\
& \mathrm{CO}_{2}+\mathrm{C} \rightarrow 2 \mathrm{CO}
\end{aligned}
$$

Min et al. (1999) and Kudrin (1985) confirm reaction between iron oxide (FeO) and carbon (C), while Min and Freuhan (1992), Sommerville et al. (1980), Dogan (2009) and Mori (1988) elucidate on the reactions between iron oxide and carbon monoxide (CO), carbon monoxide and carbon. Generally, high carbon steels are more difficult to flame cut because of the reactions between carbon, carbon monoxide and iron oxide (Higgins, 1995; MIT, 2008).

Furthermore, kinetics of reactions is generally assumed to be controlled by collision theory. In order to any reaction to happen, those particles must first collide. This is true whether both particles are in the gas state, or one is a gas and the other a solid. If the pressure is higher, the chances of collision are greater.

During flame cutting, the process involved five basic steps which include: diffusion and collision of gas molecules and/or atoms with the metal, adsorption kinetics of the reactants to the surface of the metal, reaction at the surface, desorption kinetics of products from the surface and diffusion of products away from the surface.

\section{Diffusion and collision of gas molecules and/or atoms}

At this stage, increased oxyfuel pressures lead to increased kinetics, this because increased pressure increases both the diffusion rate and the collision rates.

\section{Adsorption kinetics of the reactants to the surface of the metal}

There are two principal modes of adsorption of gas molecules on surfaces: physisorption and chemisorption. At the temperature of oxyfuel gas cutting, chemisorption is predominant. The rate of adsorption $\mathrm{R}_{\mathrm{ads}}$ of oxyfuel molecules onto surface of the cut metal can be expressed in the same manner as any kinetic process.

$$
\mathrm{R}_{\mathrm{ads}}=\mathrm{k}^{\prime} \cdot \mathrm{P}^{\mathrm{x}}
$$

where $\mathrm{x}$ is the kinetic order, $\mathrm{k}$ ' is the rate constant and $\mathrm{P}$ is the oxyfuel pressure. If the rate constant is expressed in Arrehenius form, then:

$$
\mathrm{R}_{\mathrm{ads}}=\mathrm{Ao} \exp \left(-\mathrm{E}_{\mathrm{a}} / \mathrm{RT}\right) \cdot \mathrm{P}^{\mathrm{x}}
$$

where $E_{a}$ is the activation energy for adsorption, $R$ the gas constant, $\mathrm{T}$ absolute temperature and Ao the pre-exponential factor. Generally, the rate of adsorption is governed by: the rate of arrival of gas molecules/atom at the surface, and the proportion of incident molecules which undergo adsorption, i.e.:

$$
\mathrm{R}_{\mathrm{ads}}=\mathrm{S} . \mathrm{F}
$$


where $\mathrm{S}$ is the sticking probability and $\mathrm{F}$ the incident molecular flux. The flux of incident molecules is given as:

$$
\mathrm{F}=\mathrm{P} /(2 \pi \mathrm{mkT})^{1 / 2}
$$

where $\mathrm{P}$ is gas pressure $\left(\mathrm{Nm}^{-2}\right), \mathrm{m}$ is mass of one molecule/atom (kg). The sticking probability is clearly a property of the adsorbate/ substrate system under consideration (oxyfuel and steel in this case), but must lie in the range $0<\mathrm{S}<1$. It may depend upon various factors, foremost amongst these being the existing coverage of adsorbed species $(\Theta)$ and the presence of any activation barrier to adsorption. In general:

$$
\mathrm{S}=f(\vartheta) \cdot \exp (-E a / R T)
$$

Thus, rate adsorption is expressed as:

$$
R a d s=\frac{f(\theta) \cdot P}{\sqrt{2 \pi m k T}} \cdot \exp (-E a / R T)
$$

This shows that rate of adsorption is proportional to oxyfuel pressures. Thus, $\mathrm{R}_{\mathrm{ads}}$ increases with oxyfuel pressures.

\section{Reaction at the surface}

In general, rates of chemical reactions are proportional to the concentration of the reacting substances. Increasing the pressure of a gas is exactly the same as increasing its concentration. Using the ideal gas equation:

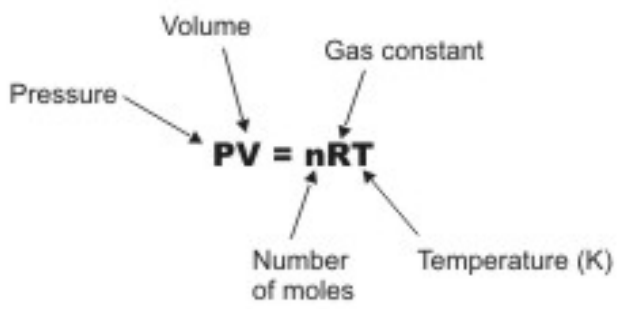

Rearranging this gives:

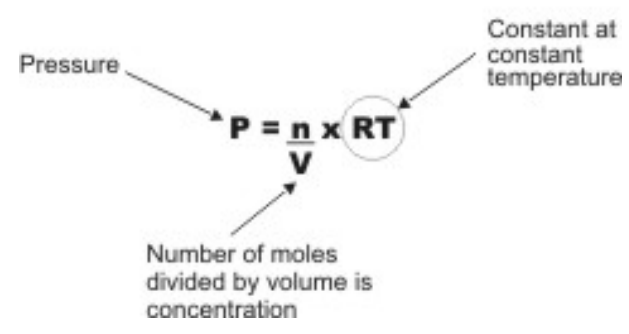

"RT" is constant as long as the temperature is constant. At the oxyacetylene cutting temperature, temperature is fairly constant. This shows that the pressure is directly proportional to the concentration. Increasing the pressure increased the cutting rates.

\section{Desorption kinetics of products from the surface}

The rate of desorption, $\mathrm{R}_{\text {des }}$, of an adsorbate from a surface can be expressed in the general form:

$$
\mathrm{R}_{\mathrm{des}}=\mathrm{kN}^{\mathrm{x}}
$$

where $\mathrm{x}$ is kinetic order of desorption, and $\mathrm{N}$ is the surface concentration of adsorbed species. In Arrhenius form:

$$
\mathrm{R}_{\mathrm{des}}=v \cdot N^{x} \cdot \exp \left(-E_{a}{ }^{\text {des }} / R T\right)
$$

Or alternatively:

$$
\mathrm{R}_{\mathrm{des}}=v \cdot f^{\prime}(\theta) \cdot \exp \left(-E_{a}{ }^{d e s} / R T\right)
$$

However,

$$
\theta=\frac{b P}{1+b P}
$$

where $\Theta$ is the surface coverage of adsorbed molecules/atoms, $b$ is a constant and $\mathrm{P}$ is pressure of the gas.

$$
\text { If: } \quad \text { b.P }<<1 \text {; then }(1+b . P) \sim 1
$$

Then

$$
\mathrm{R}_{\mathrm{des}} \sim \text { k.b.P }
$$

i.e. the desorption rate will be proportional to the pressure on the adsorbed molecules.

$$
\text { If: } \quad \text { b.P }>>1 \text {; then }(1+b . P) \sim \text { b.P }
$$

Then

$$
\mathrm{R}_{\mathrm{des}} \sim \mathrm{k}
$$

i.e., the desorption rate will be independent of the pressure on the adsorbed molecules. The acetylene pressures used ranged from 3.45 $\mathrm{x} 10^{-2} \mathrm{~N} . \mathrm{m}^{-2}$ to $5.52 \times 10^{-2} \mathrm{~N} . \mathrm{m}^{-2}$, while oxygen pressure ranged from $2.76 \times 10^{-1} \mathrm{~N} . \mathrm{m}^{-2}$ to $3.17 \times 10^{-1} \mathrm{~N} . \mathrm{m}^{-2}$. These ranges fall within the intermediary of the conditions: b.P $<<1$ and b.P $>1$. It is expected that desorption kinetics will be fairly sensitive to pressure changes. Increased pressure leads to increased rate of desorption kinetics.

\section{Diffusion of products away from the surface}

The product may diffuse into the bulk of the underlying solid. Carbon monoxide in this case and excess oxygen diffuse into the slag to the slag-steel interface through mass transport processes. Mass transport processes are known to be sensitive to concentration/pressure of the diffusing species. Also, the product of reaction at the surface may react with excess oxygen to yield a gas phase product or other surface species. The $\mathrm{CO}$ oxidation reaction is generally believed to be as the following mechanism:

$$
\begin{aligned}
& \mathrm{CO}_{(\mathrm{g})}=\mathrm{CO}_{(\mathrm{ads})} \\
& \mathrm{O}_{2(\mathrm{~g})}=2 \mathrm{O}_{(\mathrm{ads})} \\
& \mathrm{CO}_{(\mathrm{ads})}+\mathrm{O}_{(\mathrm{ads})} \stackrel{r d s}{\longrightarrow} \mathrm{CO}_{2(\mathrm{ads})} \stackrel{\text { fast }}{\longrightarrow} \mathrm{CO}_{2(\mathrm{~g})}
\end{aligned}
$$

where rds is Rate Determining Step. As $\mathrm{CO}_{2}$ is comparatively weaker bond to the surface, desorption of this product molecule is relatively faster and in many circumstances it is the surface reaction between the two adsorbed species that is the rate determining step.

If the two adsorbed molecules are assumed to be mobile on the surface and freely intermixed, then the rate of reaction will be given 
by the following rate expression for the bimolecular surface combination step:

$$
\text { Rate }=k \theta_{\text {CO. }} \theta_{O}
$$

However,

$$
\begin{aligned}
& \theta_{C O}=\frac{b_{C O} P_{C O}}{\left(1+\sqrt{b_{O} P_{O_{2}}}+b_{C O} P_{C O}\right.} \\
& \text { And } \theta_{O}=\frac{\sqrt{b_{O} P_{O_{2}}}}{\left(1+\sqrt{b_{O} P_{o_{2}}}+b_{C O} P_{C O}\right.}
\end{aligned}
$$

Combining the equations into the rate expressions gives:

$$
\text { Rate }=k \theta_{C O} . \theta_{O}=\frac{k b_{C O} P_{C O} \sqrt{b_{O} P_{O_{2}}}}{\left(1+\sqrt{b_{O} P_{O_{2}}}+b_{C O} P_{C O}\right)^{2}}
$$

This also shows sensitivity of this reaction step to oxygen pressure.

\section{Conclusion}

In general, the cutting rates decreased with carbon content of the steel. At the same oxygen pressure, cutting rates have decreased up to about $65 \%$ with increase in carbon content of about 0.17 wt $\%$. The reason for the observed trend being the retardation of the formation of $\mathrm{FeO}$ by decarburization reactions between iron oxide $(\mathrm{FeO})$ and carbon $(\mathrm{C})$, iron oxide and carbon monoxide (CO), carbon monoxide and carbon. Also, the cutting rates increased with cutting pressures of the oxyfuel gases. At the same carbon content, cutting rates have increased up to about $33 \%$. The reason for the observed trend being the increased activity of the oxyfuel gases with increase in their pressure.

\section{References}

Abuluwefa, H.T., Guthrie, R.I., Ajersch, F., 1997a, “Oxidation of Low Carbon Steel in Multicomponent Gases: Part I. Reaction Mechanisms during Isothermal Oxidation", Metallurgical and Materials Transactions A, Vol. 28A, No. 8 .

Abuluwefa, H.T., Guthrie, R.I., Ajersch, F., 1997b, "Oxidation of Low Carbon Steel in Multicomponent Gases: Part II. Reaction Mechanisms during Isothermal Oxidation", Metallurgical and Materials Transactions A, Vol. 28A, No. 8.

AWS, 1997, "American Welding Society welding Handbook", $8^{\text {th }}$ ed. New York.

AWS, 1987, "American Welding Society welding Handbook", $7^{\text {th }}$ ed. New York.

Birks, N. and Meier, G.H., 1983, "Introduction to High Temperature Oxidation of Metals", Edward Arnold, London.

DeGarmo, E.P., Black, J.T., Kosher, R.A., 1999, "Material and Processes in Manufacturing", $8^{\text {th }}$ ed. John Wiley and Sons, New York, 93 p.

Dogan, N., 2009, "Analysis of Droplet Generation in Oxygen Steelmaking”, ISIJ International, 49(1).

El-Rassi, K.P., 2000, "Rate of slag reduction in a laboratory electric furnace-alternating vs. direct current", Metallurgical and Materials Transactions $B, 31(6)$.
Fruehan, R.J., 2000, "Recent advances in the fundamentals of the kinetics of steelmaking reactions", Metallurgical and Materials Transactions, B 31(5).

Grabke, H.J., 1999, "Kinetics and mechanism of oxidation of carbon".

Higgins, R.A., 1993, "Engineering metallurgy: Applied physical metallurgy", $6^{\text {th }}$ ed., Arnold. London, 499 p.

Kofstad, P., 1988, "High Temperature Corrosion", Elsevier Science Publications Ltd., New York.

Kudrin, V., 1985, "Steel Making, English translation", Mir publisher, Moscow, pp. 72-73, 76.

Li, J., 2008, "Kinetics and Mechanism of Decarburization and Melting of Direct-Reduced Iron Pellets in Slag", Metallurgical and Materials Transactions $B$.

Li, Y., 2000, "Rate of interfacial reaction between liquid iron oxide and CO-CO2", Metallurgical and Materials Transactions B, 31(5).

MIT, 2008, http://OCW.mit.edu/NR/rdonlyres/materials-science-andengineering/3-051jspring.

Mori, K., 1988, "Kinetics of Fundamental Reactions Pertinent to Steelmaking Process", Transactions ISIJ, Vol. 28, pp 246-261.

Mróz, J., 2001, "Evaluation of the reduction of iron oxide from liquid slags using a graphite rotating disk", Metallurgical and Materials Transactions $B, 32(5)$.

Min, D.J., Fruehan, R.J., 1992, "Rate of reduction of FeO in slag by Fe-C drops", Metallurgical and Materials Transactions B, Vol. 23, No. 1, pp. 29-37.

Min, D.J., Han, J.W., Chung, W.S., 1999, "A Study of the Reduction Rate of FeO in Slag by Solid Carbon", Metallurgical and Materials Transaction B, Vol. 30, No. 2, pp. 215-221.

Poirier, D., Grandmaison, E.W., Matovic, M.D, Barnes, K.R., Nelson, B.D., 2006, "High Temperature Oxidation of Steel in an Oxygen-enriched Low NOX Furnace Environment", IFRF Combustion Journal Article Number 200602, September 2006 ISSN 1562-479X, http://www.journal.ifrf.net/200602grandmaison.html

Powell, J., Petring, D., Kumar R.V., Al-Mashikhi, S.O., Kaplan, A.F.H., Voisey, K.T., 2009, "Laser-oxygen cutting of mild steel: the thermodynamics of the oxidation reaction", J. Phys. D: Appl. Phys. 42015504.

Sarma, B., Cramb, A.W., Fruehan, R.J., 1996, "Reduction of FeO in smelting slags by solid carbon: Experimental results", Metallurgical and Materials Transactions, Vol. 27, No. 5, pp. 717-730.

Schwerdtfeger, G., Prange, R., 1984, "Exchange Current Densities for Slag-Metal Reactions. Proceedings of Second International Symposium Metallurgical Slags and Fluxes", ed. by H.A. Fine and D.R. Gaskell, RIME, New York, 595 p.

Sommerville, D., Grieveson, P., Taylor, J., 1980, Ironmaking Steelmaking, 7, $26 \mathrm{p}$.

Story, S.R., 1998, "Reduction of FeO in smelting slags by solid carbon: Re-examination of the influence of the gas-carbon reaction", Metallurgical and Materials Transactions B, 29(4).

Suarez, L., Coto, R., Vanden-Eynde, X., Lamberigts, M., Houbaert, Y., 2006, "High Temperature Oxidation of Ultra-Low-Carbon Steel", Trans Tech Publications, Switzerland Defect and Diffusion Forum, Vols. 258-260, pp. 158-163, online at http://www.scientific.net.

Teasdale, S.L., 2005, "Observations of the Reduction of FeO from Slag by Graphite, Coke and Coal Char", ISIJ International, 45(5).

Union Carbide Corp, 1975, The Oxy-Acetylene Handbook, http://en.wikipedia.org/wiki/Oxy-fuel welding and cutting\#cite refThe Oxy-Acetylene Handbook 1-4\#

Upadhyaya, G.S., Dube, R.K., 1977, "Problems in Metallurgical Thermodynamics and Kinetics", Pergamon Press, Oxford, 203 p.

Xie, D., 2003, Kinetics of reduction of ferric iron in $\mathrm{Fe}_{2} \mathrm{O}_{3}-\mathrm{CaO}-\mathrm{SiO}_{2}$ $\mathrm{Al}_{2} \mathrm{O}_{3}$ slags under argon, $\mathrm{CO}-\mathrm{CO}_{2}$, or $\mathrm{H}_{2}-\mathrm{H}_{2} \mathrm{O}$ ”, Metallurgical and Materials Transactions B, 34(2).

Zheludkevich, M.L., Gusakov, A.G., Voropaev, A.G., Vecher, A.A., Yasakau, K.A., Ferreira, M.G.S., 2004, "Influence of Oxygen Dissociation on the Oxidation of Iron", Oxidation of metals, Vol. 62, No. 3-4, pp. 223-235. 